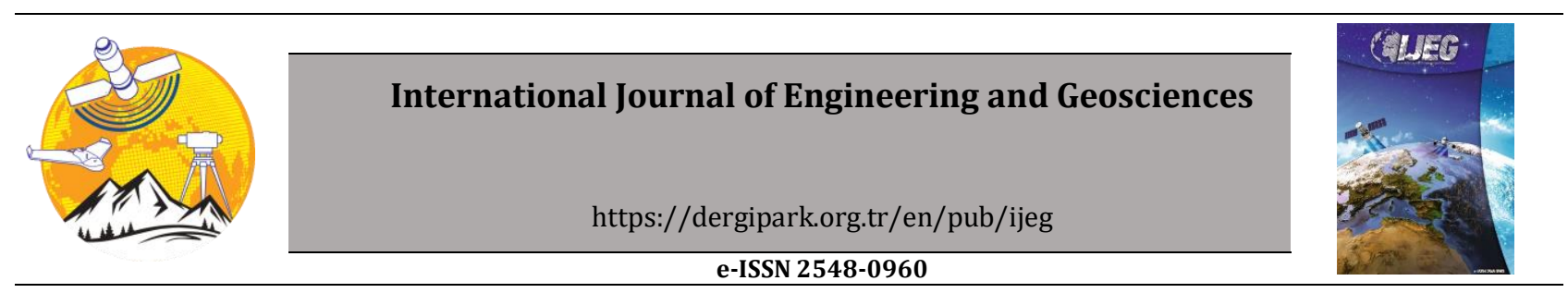

\title{
Determining highway slope ratio using a method based on slope angle calculation
}

\author{
Osman Salih Yılmaz ${ }^{* 1}$, Gülgün Özkan²®, Fatih Gülgen ${ }^{3} \odot$ \\ ${ }_{1}^{1}$ Manisa Celal Bayar University, Demirci Vocational School, Department of Architecture and Urban Planning, Manisa, Turkey \\ ${ }^{2}$ Konya Technical University, Faculty of Engineering and Natural Sciences, Department of Geomatics Engineering, Konya, Turkey \\ ${ }^{3}$ Yıldız Technical University, Faculty of Civil Engineering, Department of Geomatics Engineering, İstanbul, Turkey
}

\author{
Keywords \\ Geographic information \\ systems (GIS) \\ Highway construction \\ Stability analysis \\ Slope ratio \\ Slope angle
}

\begin{abstract}
Geographic Information System (GIS) is a vital tool used in numerous areas related to natural science and engineering studies. Managing complex data and obtaining accurate results from the analysis are essential functions of GIS. It is also efficiently used in highway designing both in project and application phases. This study proposes a new calculation method of slope angles to determine the suitable slope modal of a road by using topographic and geological datasets in a GIS environment. Using this method in the preparation phase of the project enables a more accurate calculation of earthwork volume. The proposed method was applied to a highway to prove this idea. The selected road is a significant tertiary of which project was completed by the Turkish General Directorate of Highways. In this study, the calculated values of the project were considered as references. Comparing both results obtained from the proposed method and application project, the accuracy of the slope modal of the proposed method is $71 \%$, and the accuracy of its earthwork volume is $99 \%$. The proposed approach will enable project managers and designers to determine more reliable earthwork volume during project feasibility studies without any application in the field.
\end{abstract}

\section{INTRODUCTION}

With the development of technology, the need for producing, storing, and managing information has increased. For many sectors and professional disciplines, Geographic Information Systems (GIS) is one of the fundamental tools used for answering questions about geographical affairs (Chang 2016). A wide range of applications from the management of the distributed assets of utility companies to emergency response uses GIS (Clarke 1986; Goodchild 2009). GIS technologies, it has been widely employed to support the planning and designing of different types of linear infrastructures, ranging from roads to pipelines (Effat and Hassan 2013).

In the traditional approach, highways designers determine the optimal route by considering the alternative ones. Numerous factors affect the route design, such as engineering structures, topography, ecology, geology, soil types, land use patterns, environment, and even community concerns (Sadek et al. 2000; Kim et al. 2005). Determining the most suitable route is hard, complicated, and timeconsuming without using GIS and mathematical models (Jong et al. 2000; Luettinger and Clark 2005; Ramírez-Rosado et al. 2005).

Using optimization techniques is the most suitable approach in the determination of the best route. The goal of optimization is to find the safest and least-cost planning route between two given points (Jong and Schonfeld, 2003). In literature, there are various academic studies on highway route optimization. Dijkstra (1959) algorithm, developed to determine the shortest route, is the most wellknown and commonly used one. It is also adapted to raster representation as in the gateway-shortestpath algorithm Lombard and Church (1993) and the least-cost-paths algorithm (Collischonn and Pilar 2000). Also, Eastman (1989) push broom, Tomlin (1990) spread, and Berry (2000) splash algorithms are some of the different raster representationoriented corridor siting algorithms (Aissi et al. 2012). The genetic algorithms developed by Jong

\footnotetext{
* Corresponding Author

*(osmansalih.yilmaz @cbu.edu.tr) ORCID ID 0000 - 0003 - 4632 - 9349 (gozkan@ktun.edu.tr) ORCID ID 0000 - 0002 - 0815 - 2899 (fgulgen@yildiz.edu.tr) ORCID ID 0000 - $0002-8754-9017$
} method based on slope angle calculation. International Journal of Engineering and Geosciences, 6(2), 98-103 
(1998), and Jong and Schonfeld (2003), relied on manual inputs and worked only with artificial maps. These are integrated with GIS and used in highway optimization by many researchers (Jong et al. 2000; Jha and Schonfeld, 2000a; Jha and Schonfeld 2000b; Jha, 2001a; Jha et al. 2001b; Kim et al. 2004; Jha and Schonfeld 2004; Kim et al. 2005; Jha and Kim 2006; Kang et al. 2009; Kang et al. 2012).

According to Chew et al. (1989), the factors drainage, earthwork, pavement, bridges, miscellaneous items, and land are taken into consideration in determining the route. They affect the cost of the highway directly. Their average effects are; drainage $10 \%$, earthwork $25 \%$, pavement $30 \%$, bridges $20 \%$, miscellaneous items $10 \%$, land 5-10\%, according to Organisation for Economic Cooperation and Development (OECD 1973). Among them, earthwork (25\%) is the most important part of the cost. Earthwork differs due to the length of the route, landscape, and standards of a highway and highly related to the cut incline of slope (Jha and Schonfeld 2003; Jha and Kim 2006). The cutting slope is determined with the calculations of slope angle and slope stability. In most applications, the primary purpose of slope stability analysis is to contribute to the safe and economical design of excavation, embankments, earth dams, landfills, and spoil heaps (Abramson et al. 2001). Cut slope differs due to the type of rocks. The difference in cut slope also changes the cross-section area and earthwork volume.

In most of the highway applications until now, studies have focused on route optimization. Informs of minimum cost, maximum benefit (Jha and Schonfeld, 2000a) calculating cut and fill cost 25\% accurately will increase the reliability. This study aims to determine the earthwork of cut and fill in the preliminary project, minimizing the land works inground stability, developing the cutting slope method based on GIS.

Determining the safe slope is a critical process at the designing stage of road construction. Slope stability analysis is implemented to assess the robust design of human-made slopes and the equilibrium conditions. Stability analysis and design methods for rock slopes fall into two groups; limit equilibrium analysis and numerical analysis (Wyllie and Mah 2005). Limit equilibrium analysis provides stability by using a general process that involves comparing the available shear strength along the sliding surface with the energy required to maintain the slope in equilibrium. Due to its simplicity and applicability, it has beneficial procedures that are valid on various terrain surfaces. It can be applied to different failures such as plane, wedge, circular, and toppling. The other processes, such as kinematic and empirical methods, which are known as popular ones, are also used instability analysis. The numerical study examines the stresses and strains developed in the slope to compensate for the stability. It includes continuum modeling, discontinuous modeling, and hybrid modeling (Raghuvanshi 2019).
The common fractured rocks that cover the fills in the testing area tend to behave as soil and fail in a circular mode when the slope dimensions are substantially more significant than the sizes of the rock fragments. When the material is fragile, as in a soil slope, or the rock mass is very heavily jointed or broken, as in waste rock dump, the failure is defined by a sing discontinuity surface but tends to follow a circular path (Wyllie and Mah 2005). It is one of the most probable instabilities on slopes with severely crushed rock or soil slopes (Mohtarami et al. 2014).

The proposed method used in this study enables the project managers to calculate the project cost, depending on the cut and fill amount, reliably using GIS tools. It also minimizes the groundwork and drilling that affect the value negatively concerning time and finance.

\section{STUDY AREA and DATASET}

This study was elaborated on a highway connecting Melikli, Davutlu, and Yedisehirli villages of Akdagmadeni in Yozgat province of Turkey (Figure 1). The testing route between Melikli and Yedişehirli villages indicated in a solid black line in Figure 1 is almost a total of $9.82 \mathrm{~km}$ length.

The topographic and geological maps of the region are the primary datasets used in this study. The topographic map at the scale 1:1000 obtained from the terrestrial surveys was produced by the surveying teams of the 6th Regional Directorate of the Turkish General Directorate of Highways (TGDH). The map clearly shows the rough terrain surface in the region. While the elevations on the studied route changes between $1100 \mathrm{~m}$ and $1250 \mathrm{~m}$, the average height is about $1170 \mathrm{~m}$.

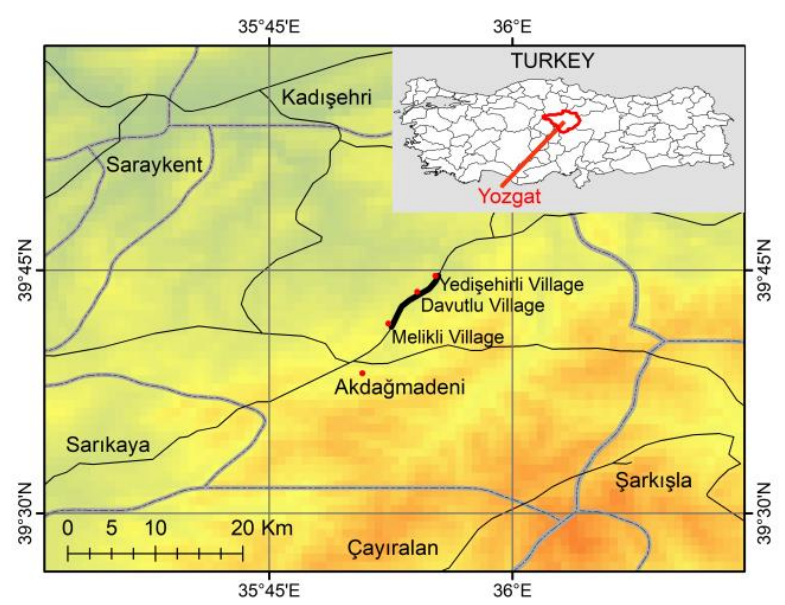

Figure 1. Highway route close to Akdağmadeni district used for experimental testing

The geological data used in this study was obtained from the geological map at the scale of 1:25 000 produced by the Turkish General Directorate of Mineral Research and Exploration. The ground of the highway route is covered by dry rocks that are broken, shattered, and without tension cracks. The geological structure is composed of Late Eocenebasaltic andesite, basaltic trachyte andesite, trachyte 
andesite, andesite, dacite, and rhyolite and formed by minerals of plagioclase, alkali feldspar, quartz, hornblende, augite, and biotite.

The soil classification and slope angle values of the relevant highway's application project were also used to be comparing the values obtained by the calculation method of the slope angle proposed in this study. According to the application project, ground classification of the first $7 \mathrm{~km}$ differs from the last $3 \mathrm{~km}$. These classifications are the values obtained by geotechnical experiments and ground drilling of TGHD (Table 1).

Table 1. Slope angles associated with the ground classes

\begin{tabular}{ccc}
\hline Part $(\mathrm{m})$ & Soil classes & Slope \\
\hline $0-6960$ & $\begin{array}{c}20 \% \text { Hard rock } \\
80 \% \text { Soft rock }\end{array}$ & $2 / 3$ \\
\hline $6960-9820$ & $\begin{array}{l}50 \% \text { Soft rock } \\
50 \% \text { Crowbar }\end{array}$ & $1 / 1$ \\
\hline
\end{tabular}

\section{METHOD}

One of the favorable environments for the integration and configuration of data collected from different sources is GIS. In route optimization studies, administers usually need a GIS environment to be able to manage data from a central point. An accurate and valid slope designing study is based on input data obtained from topographic and geological maps. In this context, the authors propose first to configure all map data in a geodatabase to derive the information needed in this study.

The average slope height along the route is determined from the topographic data. Alternatively, If there is a project team in the field, they can determine the average slope height by also performing reconnaissance.

The soil stability is depended on the safe slope angles. The stabilization analysis needs the cohesion c and friction angle $\Phi$ values. They are usually derived from the geological data of a geodatabase. Hoek (1970) has developed design graphs to simplify the calculations of failures by avoiding some of the tedious formulas (Sjöberg 1999). The design graphs generated for the circular failure provide a preliminary evaluation for stability analysis on slopes where landslips can be expected. In one of the Hoek (1970) design graphs describing the relationship between the slope angle and the slope height, the horizontal axis shows the $X$ function depending on the slope angles. The vertical axis indicates the $Y$ function correlated to the slope heights (Figure 2).

$X$ and $Y$ functions modifying the axis are explained in sample two dimensional cross-sections (Figure 3). These function formulas are related to the slope angle and slope height. According to the geological formation of the study area, the terrain formation is close to dry, and tension cracks free slopes. In this case, Eq. (1) and Eq. (2) are used to calculate functions of slope height, and slope angle in this study.

$$
\begin{aligned}
& X=I-1.2 \times \Phi \\
& \mathbf{Y}=\frac{(\gamma \times \mathbf{H})}{\mathbf{c}}
\end{aligned}
$$

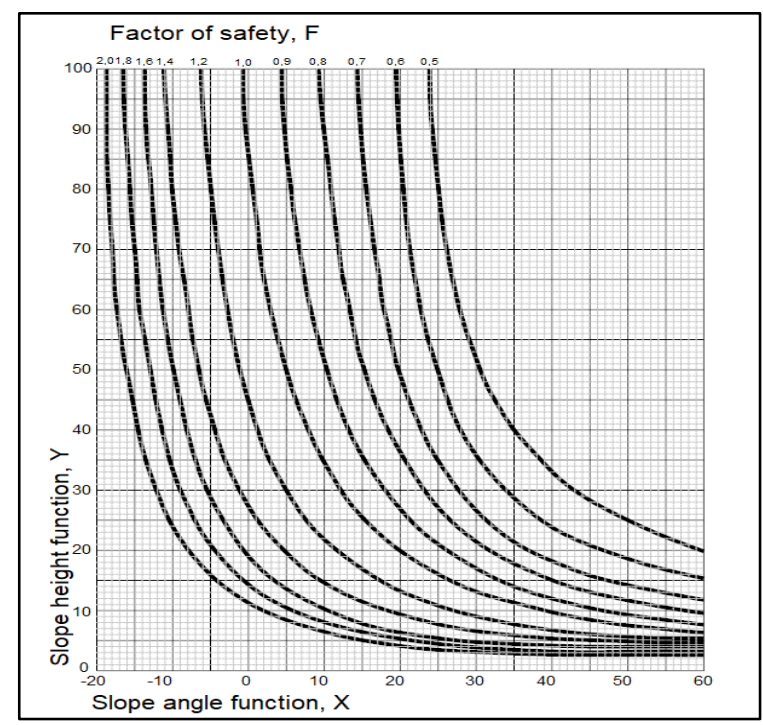

Figure 2. Circular failure design graph (Hoek 1970)

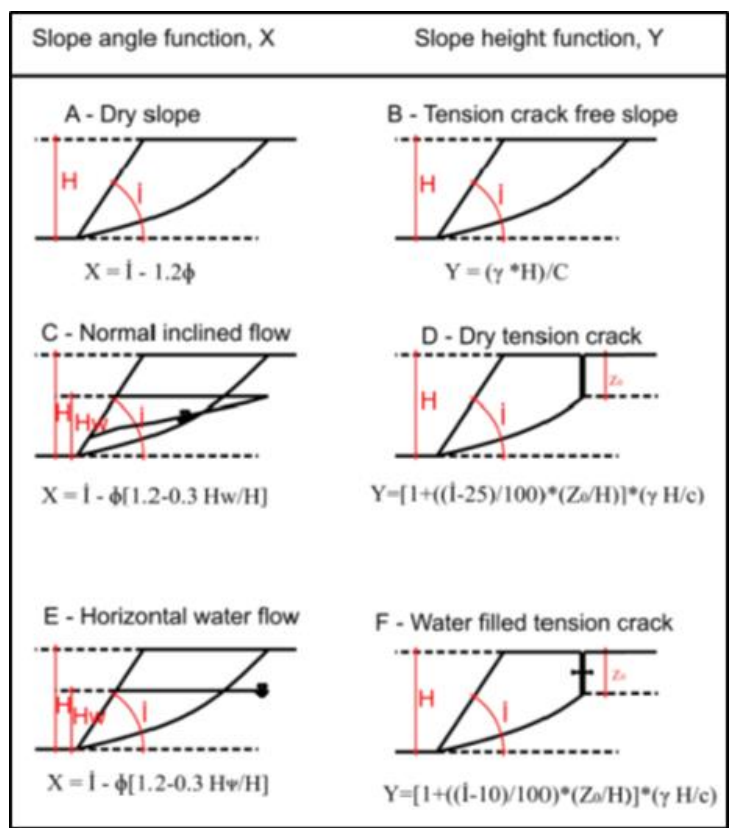

Figure 3. Slope geometry sections (Hoek 1970)

In Eq. (1) the symbol $I$ indicates the slope angle and $\Phi$ symbolizes friction angle. The fixed value of 1.2 expresses the factor of safety for the circular failure used in this study. The safety coefficient is evaluated as the ratio of the resisting force (the shear strength force acting upwards along the plane that resists sliding) to the driving force (the force acting downwards along the sliding plane) along the failure plane (Park et al. 2016). For balancing the slopes, $f>1$ is a must. In practice, 1,2 and 1,5 are chosen frequently. In this study, the value 1,2 is used. $\gamma$ indicates weight per unit, $\mathrm{H}$ shows slope height, and c symbolizes cohesion value in Eq. (2).

Ground and rock parameters of c, $\Phi$ and $\gamma$ are determined realistically by doing drilling and lab. Tests of uniaxial compressive strength, triaxial 
compressive strength. On the contrary, drilling activities and lab. Tests are time-consuming and costly. Thus, kinds of rocks and formerly calculated parameters are mostly used in engineering studies searching for ground (Wyllie and Mah 2005).

The cohesion values, friction angle, and rock types of each layer, constituted by Hoek and Bray (1974), are added to the related fields of each feature class table. Due to the study region formed by dry and tension crack free slopes, the slope angle is explained using the circular failure design graph. Lastly, the tight slope angle I obtained from Eq. (1).

The most suitable slope design is applied by considering the calculated secure angle. Figure 4 indicates the standard gradients of the cut slope used in highway studies.

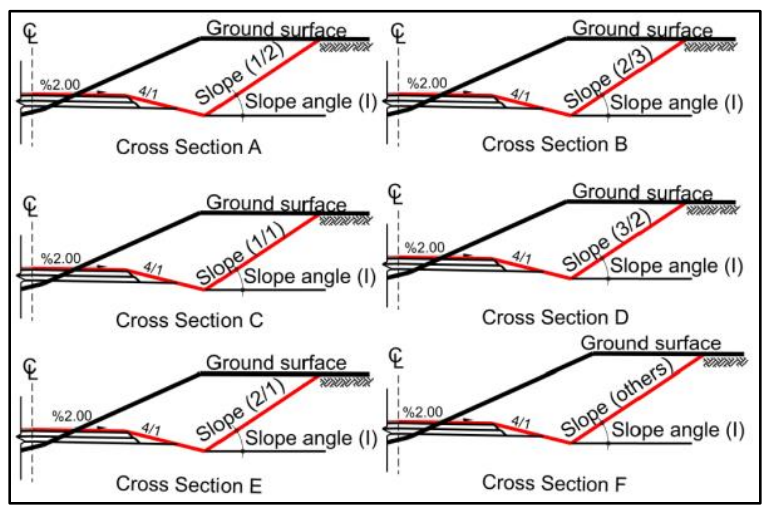

Figure 4. Slope ratios

\section{RESULTS}

In this study, the slope height was selected $10 \mathrm{~m}$ by considering the contours of the topographic map and the geological formations of the study area. The cohesion and the unit volume weight are $300 \mathrm{kN} / \mathrm{m}^{2}$ and $220 \mathrm{~kg} / \mathrm{m}^{3}$, respectively, using a script developed in the GIS environment. The slope height value of 73.33 is calculated from Eq. (2), and its associated slope angle value extracted from the graphic in Figure 2 was -3. Due to the selected safety factor 1.2 , the slope angle is calculated as $50^{\circ}$ by using Eq. (1). According to the calculated slope angle, the slope ratio of $2 / 3$ is chosen as the best cut slope (Figure 4b).

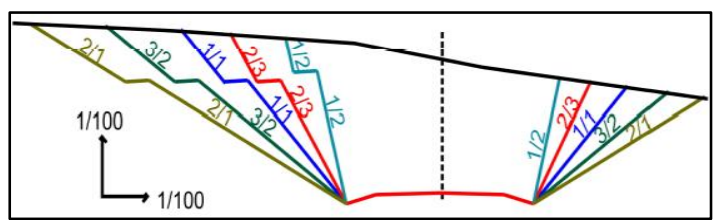

Figure 5. Five types of slope ratios used in the TGHD's specification

\section{DISCUSSION}

For checking the validity of the proposed method, the chosen ratio is compared with the data of the reference project performed by TGDH. The assessments on the robustness of the proposed method are discussed in two stages. First, the accuracy of the recommended slope ratio is scrutinized. Then, the excavation quantities of the other slope ratios are presented for comparison (Table 2).

Table 2. Data comparison between the proposed method and the application project

\begin{tabular}{ccccc}
\hline Alternatives & Slope & Part & $\begin{array}{c}\text { Vol. } \\
\left(\mathrm{m}^{3}\right)\end{array}$ & $\begin{array}{c}\text { Total } \\
\left(\mathrm{m}^{3}\right)\end{array}$ \\
\hline 1(Proposed) & $2 / 3$ & $0-9820$ & 64998 & 64998 \\
2 & $1 / 1$ & $0-9820$ & 85765 & 85765 \\
3 & $1 / 2$ & $0-9820$ & 39241 & 39241 \\
4 & $3 / 2$ & $0-9820$ & 23073 & 230730 \\
5 & $2 / 1$ & $0-9820$ & 60909 & 609090 \\
\hline Application & $2 / 3$ & $0-6960$ & 64771 & 65030 \\
Project & $1 / 1$ & $6960-9820$ & 259 & \\
\hline
\end{tabular}

\subsection{Discussion of Slope Ratios}

According to TGHD's application project, the $2 / 3$ slope ratio was applied to the first $6960 \mathrm{~m}$ (Figure 4c). This ratio is compatible with the rate designed depending on the calculation of the slope angle proposed in our methodology. The consistent part is about $71 \%$ of the total length of the route. On the other hand, the $1 / 1$ slope ratio was employed for the remaining $2860 \mathrm{~m}$ apart in the reference data (Figure 4c). The rates in the result of this study and application project differ for this part of the route.

\subsection{Discussion of Earthwork Volume}

One of the vital issues that should be finding solutions in highway projects is to calculate earthwork volume that affects the project cost in the preparation phase. The project managers make this calculation by using a digital terrain model (DTM). There are three sources of DEM data: terrestrial survey techniques, topographic maps, and image data acquired from remote sensing (Nelson et al. 2009). In this study, the DTM is produced from irregularly distributed elevation points collected from the ground survey by the sixth regional directorate of TGDH using the TopotoRaster interpolation algorithm (Hutchinson 1989). The algorithm uses the typography and hydrography data combining with the irregularly distributed elevation points to produce a hydrologically corrected DTM (Gülgen and Gökgöz 2010).

From the DTM, the cross-sections of $20 \mathrm{~m}$ intervals along the test path were extracted (Figure 5). The highway designers can apply one of the slope ratios from the five types used in the TGHS's highway specification. Table 2 indicates the calculated excavation volumes for each slope ratio.

According to the application project, the total earthwork volume calculated from both ratios is 65 $030 \mathrm{~m}^{3}$. The earthwork volume obtained from $2 / 3$ type cross-section, which is also proposed in this study, is $64998 \mathrm{~m}^{3}$. Thus, the difference between the two obtained results is $23 \mathrm{~m}^{3}$. The success of the proposed method is $99.95 \%$ regarding earthwork volume. If the $1 / 1$ ratio were used along the entire route, the success rate would be $75.8 \%$. Likewise, the success rate would be $60.3 \%, 28.2 \%$, and $10.7 \%$ for the $1 / 2,2 / 3$, and $2 / 1$ slope ratios, respectively. 
These results indicate that earthwork volume increases while the incline of the slope decreases. The increase in volume points out the importance of using a proper slope ratio in engineering applications.

\section{CONCLUSION}

One of the essential processes in designing a highway is to find the optimum one from the alternative routes. Engineering structures, topography, ecology, geology, soil types, land use patterns, environment, and even community concerns are some of the factors that affect the selection of the optimum route. All of these are closely related to the cost of highway design. After the choice of optimum path, the engineers calculate the cost values of the construction of highway structures at the second stage of the highway design. In this study, we focus on the evaluation of earthwork volume, which is an essential factor affecting the cost. When the proposed method that contributes to calculating proper slope angles considering the geological structure of the land is used, the engineers precisely determines the amount of earthwork volume. Thus, the cost can be calculated. Although it suggests using an average slope angle along the entire route, the earthwork volume is quite close to a reference value used in the application project.

Highway engineers can utilize the geospatial analysis capabilities of GIS in the highway designing project. Commonly, the GIS enables (1) to integrate geological and topographical data obtained from different sources, (2) to reach the attribute data stored in a geospatial database, (3) to create the DTM used in each calculation step of the project. In this study, the calculations necessary for stability analyzes were made in the GIS environment. The required equations were taken from Hoek (1970), and GIS integration was provided with a script.

Apart from highway projects, the proposed method may be used in a different project that uses land stability such as speed train, dam, pond, and pipeline applications to calculate the cost at the preparation stage. On the other hand, the most significant deficiency of the proposed ratio is the suggestion of an average slope ratio based on the calculated angles along the route. However, different slope ratios may need to be applied for a road, as seen in the application project carried out in this study. In the future, we are going to plan to add a decision-making system to the proposed method to consider the needs of slope changes along the route.The decision-making system integrated with GIS will provide a more accurate calculation of slope angles.

\section{REFERENCES}

Abramson L W, Lee T S, Sharma S \& Boyce G M (2001). Slope stability and stabilization methods. John Wiley \& Sons. ISBN: 9780471384939

Aissi H, Chakhar S \& Mousseau V (2012). GIS-based multicriteria evaluation approach for corridor siting. Environment and Planning B: Planning and Design, 39(2), 287-307. DOI: $10.1068 / \mathrm{b} 37085$

Berry J K (2000). Analyzing accumulation surfaces. Map Analysis: Procedures and Applications in GIS Modelling Technical Report. Berry and Associates//Spatial Informations Systems Inc.

Chang K T (2016). Introduction to geographical information systems. $8^{\text {th }}$ edition. McGraw Hill. New York, USA.

Chew E P, Goh C J \& Fwa T F (1989). Simultaneous optimization of horizontal and vertical alignments for highways. Transportation Research Part B: Methodological, 23(5), 315329. DOI: 10.1016/0191-2615(89)90008-8

Clarke K C (1986). Advances in Geographic information systems. Computers, Environment and Urban Systems, 10, 175-184. DOI: 10.1016/0198-9715(86)90006-2

Collischonn W \& Pilar J V (2000). A direction dependent least-cost-path algorithm for roads and canals. International Journal of Geographical Information Science, 14(4), 397406. DOI: $10.1080 / 13658810050024304$

Dijkstra E W (1959). A note on two problems in connexion with graphs. Numerische Mathematik, 1(1), 269-271.

Eastman J R (1989). Pushbroom algorithms for calculating distances in raster grids. In Proceedings Autocarto, 9, 288-297.

Effat H A \& Hassan O A (2013). Designing and evaluation of three alternatives highway routes using the Analytical Hierarchy Process and the least-cost path analysis, application in Sinai Peninsula, Egypt. The Egyptian Journal of Remote Sensing and Space Sciences, 16(2), 141151. DOI: $10.1016 /$ j.ejrs.2013.08.001

Goodchild M F (2009). Geographic Information System. Encyclopedia of Database Systems. Springer, Boston, MA: Springer US.

Gülgen F \& Gökgöz T (2010). A new algorithm for extraction of continuous channel networks without problematic parallels from hydrologically corrected DEMs. Boletim de Ciências Geodésicas, 16(1), 20-38.

Hoek E (1970). Estimating the stability of excavated slopes in opencast mines. Institution of Mining and Metallurgy A, 105, A132.

Hutchinson M F (1989). A new procedure for gridding elevation and stream line data with automatic removal of spurious pits. Journal of Hydrology, 106(3-4), 211-232. DOI: 10.1016/0022-1694(89)90073-5

Jha M K \& Kim E (2006). Highway route optimization based on accessibility, proximity, and land-use changes. Journal of Transportation EngineeringAsce, 132(5), 435-439. 
Jha M K \& Schonfeld P (2000a). Geographic Information System-Based Analysis of Right-ofWay Cost for Highway Optimization. Transportation Research Record, 1719(1), 241249. DOI: $10.3141 / 1719-32$

Jha M K \& Schonfeld P (2000b). Integrating genetic algorithms and geographic information system to optimize highway alignments. Transportation Research Record, 1719(1), 233240. DOI: $10.3141 / 1719-31$

Jha M K \& Schonfeld P (2003). Trade-offs Between Initial and Maintenance Costs of Highways in Cross-Slopes. Journal of Infrastructure Systems, 9(1), 16-25.

Jha M K \& Schonfeld P (2004). A highway alignment optimization model using geographic information systems. Transportation Research Part A: Policy and Practice, 38(6), 455-481. DOI: 10.1016/j.tra.2004.04.001

Jha M K (2001a). Using a geographic information system for automated decision making in highway cost analysis. Transportation Research Record, 1768(1), 260-267. DOI: 10.3141/176830

Jha M K, McCall C \& Schonfeld P (2001b). Using GIS, genetic algorithms, and visualization in highway development. Computer-Aided Civil and Infrastructure Engineering, 16(6), 399-414.

Jong J C \& Schonfeld P (2003). An evolutionary model for simultaneously optimizing threedimensional highway alignments. Transportation Research Part B: Methodological, 37(2), 107-128. DOI: 10.1016/S0191-2615(01)00047-9

Jong J C (1998). Optimizing highway alignments with genetic algorithms. PhD Thesis. University of Maryland, College Park.

Jong J C, Jha M K \& Schonfeld P (2000). Preliminary highway design with genetic algorithms and geographic information systems. ComputerAided Civil and Infrastructure Engineering, 15(4), 261-271.

Kang M W, Jha M K \& Schonfeld P (2012). Applicability of highway alignment optimization models. Transportation Research Part C: Emerging Technologies, 21(1), 257-286. DOI: $10.1016 / j . t r c .2011 .09 .006$

Kang M W, Schonfeld P \& Yang N (2009). Prescreening and repairing in a genetic algorithm for highway alignment optimization. Computer-Aided Civil and Infrastructure Engineering, 24(2), 109-119.

Kim E, Jha M K \& Son B (2005). Improving the computational efficiency of highway alignment optimization models through a stepwise genetic algorithms approach. Transportation Research
Part B: Methodological, 39(4), 339-360. DOI: 10.1016/j.trb.2004.06.001

Kim E, Jha M K, Lovell D J \& Schonfeld P (2004). Intersection modeling for highway alignment optimization. Computer-Aided Civil and Infrastructure Engineering, 19(2), 119-129.

Lombard K \& Church R L (1993). The gateway shortest path problem: generating alternative routes for a corridor location problem. Geographical Systems, 1, 25-45.

Luettinger J \& Clark T (2005). Geographic information system-based pipeline route selection process. Journal of Water Resources Planning and Management, 131(3), 193-200.

Mohtarami E, Jafari A \& Amini M (2014). Stability analysis of slopes against combined circulartoppling failure. International Journal of Rock Mechanics and Mining Sciences, 67, 43-56. DOI: 10.1016/j.ijrmms.2013.12.020

Nelson A, Reuter H I \& Gessler P (2009). DEM production methods and sources. Developments in Soil Science, 33, 65-85. DOI: 10.1016/S0166-2481(08)00003-2

OECD (1973). Optimisation of Road Alignment by the Use of Computers. Organisation for Economic Co-operation and Development. ISBN: 9789264111066

Park H J, Lee J H, Kim K M \& Um J G (2016). Assessment of rock slope stability using GISbased probabilistic kinematic analysis. Engineering Geology, 203, 56-69. DOI: 10.1016/j.enggeo.2015.08.021

Raghuvanshi T K (2019). Plane failure in rock slopes - A review on stability analysis techniques. Journal of King Saud University - Science, 31(1), 101-109. DOI: 10.1016/j.jksus.2017.06.004

Ramírez-Rosado I J, Fernández-Jiménez L A, GarcíaGarrido E, Zorzano-Santamaria P, Zorzano-Alba E, Miranda V \& Monteiro C (2005). Advanced model for expansion of natural gas distribution networks based on geographic information systems. Analysis (Cell Size), 468(067), 280.

Sadek S, Kaysi I \& Bedran M (2000). Geotechnical and environmental considerations in highway layouts: An integrated GIS assessment approach. International Journal of Applied Earth Observation and Geoinformation, 2(3-4), 190-198. DOI: 10.1016/S03032434(00)85013-8

Sjöberg J (1999). Analysis of large scale rock slopes. PHD Thesis, Luleå tekniska universitet, Sweden.

Tomlin C D (1990). Geographic information systems and cartographic modeling. Prentice Hal, New Jersey, US. ISBN 0-13-350927-3

Wyllie D C \& Mah C W (2005) Rock Slope Engineering. 5th edition. Taylor\&Francis, New York, USA. ISBN: 0-203-57083-9 